\title{
ACTUAR (Y) SORPRENDER (Y) SUGERIR. LA CONVIVENCIA PRAGMÁTICA DE LOS DISCURSOS COTIDIANOS, CÓMICOS Y POÉTICOS, BASE DE UNA TEORÍA DE LA FICCIÓN
}

\section{ACT (AND) SURPRISE (AND) SUGGEST. THE PRAGMATIC COEXISTENCE OF EVERYDAY, COMICAL AND POETIC DISCOURSES, BASIS OF A FICTION THEORY}

\author{
Laro DEL RÍO CASTAÑEDA \\ Universidad de Oviedo \\ riolaro@uniovi.es
}

Resumen: La teoría de la relevancia de Sperber y Wilson permite entender los discursos cotidianos, cómicos y poéticos desde un nuevo enfoque. Ya no es necesario pensar en un proceso comunicativo independiente para cada uno de ellos, sino que podemos explicarlos como tipos de uso de un proceso comunicativo complejo. Esta perspectiva nos obliga a reconsiderar algunos conceptos tradicionales de la teoría de la literatura, como no ficción, autoficción o canon. Tomando como base esas premisas, en el presente artículo se propone una definición de la noción de ficción.

Palabras clave: Teoría de la ficción. Pragmática. Recepción. Teoría de la literatura. Humor.

\begin{abstract}
Sperber and Wilson's Relevance Theory allows us to understand everyday, comical and poetic discourses from a new scope. It is no longer necessary to formulate an independent communicative process for each one of them. On the contrary, they can be explained as different uses of one large and complex process. This perspective forces us to reconsider some traditional Literary Theory concepts, such as nonfiction, autofiction or canon. Taking these premises as a starting point, this article aims to propose a definition of fiction.
\end{abstract}

Keywords: Theory of Fiction. Pragmatics. Reception. Literary Theory. Humor. 
What this show is is a metaphorical preposition that explains the relationship between what you think you think you see me think and what I'm genuinely able to think.

Hannah Gadsby, Douglas.

\section{INTRODUCCIÓN: LA PARTE POR EL TODO}

Las conversaciones, los chistes y la literatura son tipos de discurso claramente distintos. Así los ha tratado la tradición. Sin embargo, en el mundo académico uno de los ejercicios más habituales de las últimas décadas ha consistido en desmontar esta taxonomía, tratar de difuminar las fronteras, hallar un origen común, unos mecanismos y unos efectos compartidos por el discurso coloquial, el cómico y el poético ${ }^{1}$. La desconfianza que nos generan los grandes metarrelatos - el extendido gusto por lo parcial y por lo ambiguo propio del postestructuralismo - invita a asumir esta postura: parece que es hora de derrumbar barreras, igualar diferencias, desestructurar jerarquías, deconstruir palabras, desintegrar conceptos, fundir ideas.

Este es un objetivo legítimo. Teorizar es destruir y construir, todo a un mismo tiempo (Althusser, 1970), y los beneficios del desmantelamiento post- son tan evidentes que no hace falta repetirlos aquí. De hecho, coincidimos con la mayoría de las tesis de los autores que participan de este enfoque, tal y como se verá a lo largo del artículo. Pero el propósito que sigue el presente texto es afinar algunos aspectos del fenómeno comunicativo de las conversaciones, los chistes y la literatura, admitiendo su vertebración única al mismo tiempo que señalando sus tendencias divergentes. Nuestra tesis principal se sintetiza en que, si bien los tres discursos funcionan gracias a los mismos procedimientos, mecanismos y efectos - elementos que la pragmática ha sabido definir y analizar en una teoría de la comunicación unitaria, coherente y realista-, cada uno de ellos puede ser explicado como propio de una parte de ese gran proceso. Son lo mismo, en la medida en que están constituidos por las mismas entidades, se apoyan en las mismas necesidades y provocan los mismos resultados en el receptor; son distintos en la medida en que apelan a momentos o recursos distintos dentro del macroproceso comunicativo.

Por ello, para llevar a cabo esta investigación, acudiremos a la terminología que nos brinda la pragmática, a medio camino entre la filosofía del lenguaje, la neurolingüística y los estudios hermenéuticos. Se desglosarán y definirán los pasos que seguimos los seres humanos cuando somos receptores de un mensaje y se trazarán relaciones entre cada tipo de discurso y cada faceta del proceso inferencial.

\footnotetext{
${ }^{1}$ Por razones de estilo, utilizaremos indistintamente los términos cotidiano, conversacional y coloquial, así como cómico, chistoso y humorístico, y poético, literario y lírico. Somos conscientes de que, en estudios posteriores, será necesario ahondar en los matices de cada concepto.
} 


\section{EL MACROPROCESO COMUNICATIVO (I): LA EXPLICATURA ENRIQUECIDA}

Aunque Sperber y Wilson (1994) quieran evitar resultar sentenciosos y nieguen esta idea, somos de la opinión de que toda comunicación humana sigue el modelo ostensivoinferencial que estos autores propusieron en su texto Relevancia. Una vez que se ha captado el mensaje como mensaje, enviado por un emisor a quien asignamos la intención comunicativa, pasamos a realizar una serie de labores que nos permiten entender -en sentido pleno, más allá de descifrar - el bloque de información recibido.

Existen tres procesos pragmáticos -normalmente inconscientes- que complementan la descodificación semántica, si bien hay que tener en cuenta que no son secuenciales, sino que están entrelazados, interaccionan entre sí y con la mencionada descodificación. Son la asignación de referentes, la desambiguación y el enriquecimiento. Acceden a ingredientes que están fuera del código, de por sí vago o insuficiente, de las lenguas humanas: no es posible entender una oración atendiendo exclusivamente al binomio significante-significado; hemos de contextualizar, aportar datos, ubicar los entes referenciados, descubrir a qué lugar fuera del texto apuntan los significados. Con ellos se establecen lazos entre sujeto, código y realidad, y se construye la explicatura, el enunciado contextualizado y lleno de sentido, preparado para intervenir en la presuposición inferencial: la elaboración de las implicaturas, información de segundo grado en la comunicación, que más tarde tendremos tiempo de comentar.

El primer mecanismo, la asignación de referentes, solventa el problema del tercer vértice del signo (junto a significante y significado), si seguimos la propuesta de Peirce y de la semiótica posterior. Cuando utilizamos un deíctico, un pronombre o un nombre propio, necesitamos ponerlo en relación con el mundo empírico ${ }^{2}$. En una situación dada, Julio César quiere una buena copa solo será comprensible si somos capaces de saber a qué entidad se denota con Julio César. Teniendo esa información, podremos finalmente buscar y determinar la relevancia del resto de elementos que constituyen el enunciado y del enunciado en su conjunto. Saber de qué parte de la realidad estamos hablando nos sitúa en una perspectiva, nos activa un entorno cognitivo particular y determinante para el resto de la interpretación: pone a disposición de nuestra mente una serie de informaciones, las transforma en contexto, las hace más accesibles que el resto de datos almacenados en la memoria para que podamos utilizarlas durante la comunicación. Este reenfoque del entorno cognitivo es constante y también condiciona y depende de los demás mecanismos que llevamos a cabo cuando somos receptores de un mensaje.

El segundo instrumento para la construcción de la explicatura, la desambiguación, tiene que ver con aquellos significantes que constan de más de un significado asociado. Las palabras polisémicas requieren ser podadas de sentidos posibles. En una situación

\footnotetext{
${ }^{2}$ Con mundo empírico incluimos todo lo percibido, creído o pensado por el receptor. Es posible, por ejemplo, hacer referencia a entidades ficcionales, que habitan un mundo posible distinto del factual. Utilizamos referente no como lo hacían Frege o Russell, sino como lo usa Doležel (1999).
} 
dada, Julio César quiere una buena copa únicamente será comprensible si somos capaces de saber qué significa la palabra copa, si 'vaso con pie para beber', 'unidad de consumo de bebida alcohólica' o 'carta del palo de copas', por seleccionar solo tres de las dieciséis acepciones que lista el Diccionario de la Lengua Española de la RAE. Nuestro conocimiento del código lingüístico no es suficiente para entender este enunciado, ni siquiera en una conversación aparentemente sencilla o estereotipada, como puede ser una conversación de bar. Para descubrir lo comunicado se necesita, al menos, ponerlo en relación con el cotexto, los supuestos comúnmente manifiestos del interlocutor (intuidos mediante la capacidad metarrepresentacional) y los conocimientos enciclopédicos que hemos adquirido a lo largo de nuestra experiencia vital. Seguimos, pues, afinando la explicatura a la vez que activamos el entorno cognitivo adecuado para la interpretación.

El enriquecimiento es el tercer proceso pragmático que trataremos en este apartado. Consiste en completar el significado de significantes laxos, generales, imprecisos. Los comparativos, las preposiciones o los adjetivos normalmente solo pueden ser entendidos si son aplicados, si su sentido se condensa, precisa y restringe según el uso contextual y cotextual. Así, en una situación dada, Julio César quiere una buena copa solo será comprensible si somos capaces de saber qué significa la palabra buena en relación con copa. ¿Una copa de gran tamaño, de gran valor, de gran calidad, de gran utilidad? Todas estas concepciones de la bondad conviven en la palabra, encadenadas por parecidos de familia, pero en cada uso particular solo apelamos a algunas de ellas. Las otras, como mucho, quedan relegadas a un papel connotativo.

Gracias a estos tres mecanismos, en conclusión, el ser humano completa la información codificada en la morfología, la sintaxis y el léxico del mensaje lingüístico y concreta su significado explícito, unívoco y directo: se establece la explicatura.

\section{EL MACROPROCESO COMUNICATIVO (II): LOS ACTOS DE HABLA}

Pero la explicatura solo conforma una parte de lo comunicado. Es posible entender - palabra por palabra - todo el enunciado, los referentes denotados, las acepciones individuales y precisas, y sin embargo no captar el motivo y la razón de que una persona nos lo haya hecho llegar. Desde los sesenta, gracias a Austin (1981), sabemos que las palabras hacen cosas, que la comunicación es bastante más que la transmisión de información (o la transformación intencionada del entorno cognitivo de un receptor a través de la ostentación de un estímulo comunicativo y la emisión de un contenido descodificable, por traducirlo a la terminología de Sperber y Wilson). La comunicación también permite establecer lazos afectivos, connotar, apelar, prometer, afirmar, insultar, halagar, desposar y otras muchas cosas más. Lo vemos en la pareja que se repite una y otra vez lo mucho que se quiere, que afirma (y en ese momento, actúa) te cedo el último pedazo de tarta o que da el sí, quiero en el altar: hablar es reforzar una relación, hablar es conceder una propiedad, hablar es constituirse como casado según el rito social del matrimonio. Otras veces, hablar es querer informar, pero suelen ser las menos. 
Para captar esos efectos es necesario tomar la explicatura, todavía inestable en este momento de la interpretación, verificarla con las estrategias inferenciales y —aquí viene el aspecto importante - ligarlo a una intención. Hablar es un acto que otra persona se ha molestado en hacer: alguien nos envía un mensaje para que hagamos algo (¿el qué?, eso tendremos que deducirlo) con ello. El hecho de que la teoría de la relevancia de Sperber y Wilson, que continúa el linaje de las máximas de Paul Grice, ponga énfasis en el acomodo entre esfuerzo y rédito cognitivos, entre proceso y beneficio, nos permite ver con claridad por qué sabe adaptarse a una teoría de la comunicación donde el signo no es el centro, sino un elemento (importante) más. El rédito cognitivo, el beneficio de la comunicación, puede ser la acumulación de información, tal y como se entendió durante siglos, pero también puede no serlo. En este sentido, la operatividad de este modelo es mayor que la del tradicional modelo del código.

Pongamos un ejemplo sencillo. Cuando una profesora les dice a sus alumnas, al pedirles un trabajo por escrito, el autocorrector de Word a veces falla, no está simplemente informando: las alumnas saben que el autocorrector puede fallar. La relevancia del acto de habla no se satisface con los cambios en el entorno cognitivo de las chicas (una mera recuperación de supuestos que ya poseían, que ya estaban almacenados en la memoria o que, en todo caso, podrían haber sido deducidos de forma muy fácil sin necesidad de invertir el gasto cognitivo que propone la profesora). Descodificar y enriquecer el enunciado solo resulta rentable si inferimos la actitud del emisor frente a su enunciado, la intención que le asociamos: ¿para qué le sirve enviar datos ya conocidos?, ¿con qué objetivo lo hace? La respuesta solo puede ser, por una serie de deducciones e inferencias que se comentarán en el siguiente apartado, que la profesora no informa, sino que avisa y manda prestar atención a las faltas ortográficas que las alumnas suelen cometer, porque Word no siempre las capta.

Cabe señalar que esa aparente indecisión entre avisar y mandar, acciones distintas, se debe al hueco entre el código y la interpretación. Cuanto más nos separamos del texto, del significado-significante, más espacio estaremos abriendo: más habremos de poner de nuestra parte y menos responsabilidad tendrá el autor. Cómo se explica esto lo veremos a continuación.

\section{EL MACROPROCESO COMUNICATIVO (III): LAS IMPLICATURAS DÉBILES}

Hemos afirmado que a partir de la explicatura es posible deducir el sentido pleno del mensaje. Las premisas y las conclusiones implicadas en esta labor deductiva se extraen de la explicatura, el contexto y la actitud proposicional (la manera de retener las proposiciones). Las premisas se recuperan de la memoria y las conclusiones se deducen de la explicatura y el contexto. En otras palabras, tanto la explicatura como la implicatura se construyen a partir de información que el receptor supone que ambos, emisor y receptor, tienen en común: datos que los dos saben que el otro sabe (lo que genera un 
círculo vicioso: el receptor supone que el emisor supone que el receptor supone que el emisor supone...) sobre el contexto, el cotexto y los propios emisor y receptor.

Al considerar que la comunicación no es literal, que no puede explicarse recurriendo a un código biunívoco y perfecto, sino que ha de construirse empleando materiales variables, cambiantes, presuntamente intersubjetivos y siempre supuestos, hay que asumir que la posibilidad de extraer implicaturas no está limitada. Todos los mensajes están abiertos a la reinterpretación, a la corrección, a una búsqueda más profunda de lo que se quiso decir. Dependiendo de en qué casos, obtener una implicatura puede ser suficiente para cubrir la necesidad de relevancia; otras veces, podemos vernos envueltos en una situación difícil de comprender, exigente en términos económico-cognitivos, que perseguimos interpretar bajo la promesa de un rendimiento muy alto. A mayor esfuerzo cognitivo, mayor beneficio hermenéutico. En la comunicación humana siempre reina el ideal de esta compensación, aunque en ocasiones no se cumpla.

Ahora bien, la fuerza de esos supuestos recuperados e inferidos no es siempre la misma. Cuanto más fuertes sean (mejor argumentados, más evidentes, más lógicos, más deducibles), mayor responsabilidad de lo comunicado recaerá en el emisor; cuando se vayan volviendo más débiles, la responsabilidad irá transfiriéndose al receptor. Hasta el punto de que es difícil saber dónde termina la comunicación como tal: el límite entre qué es una implicatura y qué es una reflexión totalmente alejada del mensaje emitido resulta muy difícil de precisar.

Hemos argumentado que existe un continuo de casos, desde implicaturas que se esperaba específicamente que el oyente recuperara hasta implicaturas que meramente se pretendía hacer manifiestas, e incluso modificaciones ulteriores del entorno cognitivo mutuo del hablante y del oyente que el hablante sólo pretendía en el sentido de que quería que su enunciado fuera relevante $y$, por consiguiente, que tuviera unos efectos cognitivos ricos y no completamente predecibles. Los pragmatistas y los semiotistas que sólo consideran las formas más fuertes de implicatura tienen una imagen sumamente distorsionada de la comunicación verbal (Sperber y Wilson, 1994: 248).

A nuestro parecer, la asignación de un valor en tanto que acto de habla acostumbra a funcionar como una implicatura fuerte ${ }^{3}$. Es un primer gesto general, que engloba a la totalidad del mensaje. En cambio, los pequeños detalles, las connotaciones más personales, las sutilezas irónicas o de tono, las lecturas políticas... demandan una mayor participación del receptor, un mayor alejamiento del texto, un mayor apoyo de premisas generadas por el sujeto intérprete. En otras palabras: son más débiles.

Estas implicaturas débiles en muchas ocasiones funcionan como efectos casi inesperados, "de segunda", rastros de la escritura, puntos de contacto por lo general

\footnotetext{
${ }^{3}$ Está abierto el debate de si considerar la asignación de una actitud a la explicatura pertenece al proceso de construcción de la explicatura o es ya parte de la construcción de la implicatura. No es un asunto que nos interese dilucidar aquí. Nuestra argumentación funciona en cualquiera de los dos casos. Mantenemos la idea de que conforma una implicatura fuerte porque, a nuestros ojos, transmite mejor la polaridad entre lenguaje coloquial y lenguaje poético que se verá más adelante.
} 
imprevistos que se forman en ese vacío existente entre el código y el entorno cognitivo del receptor, brillos conceptuales que siempre aparecen mínimamente, que a veces son susceptibles de surgir en grandes cantidades y que, con todo, tienden a pasar desapercibidos. Es cierto que, aunque sea de una forma inconsciente, su presencia es recibida por el individuo que escucha o lee. Pero hace falta prestar atención a esas iridiscencias para entenderlas plenamente, para conformarlas (darles forma), para captar sus matices y, sobre todo, para traducir la lectura en crítica (Barthes, 2005), en escritura: para hacer(las) discurso. Siguiendo al Barthes de los sesenta y primeros setenta, ese paso conlleva una reducción del texto, que de por sí es pluralidad irreductible, es explosión y diseminación, es paradoja (Barthes, 1994b; y en otros sitios).

\section{UN PROCESO, MUCHOS USOS (I): LO COTIDIANO ES HACER}

Todos y cada uno de los elementos y procedimientos vistos hasta el momento aparecen en todos y cada uno de los actos comunicativos lingüísticos. Según decíamos en un principio, una conversación informal cualquiera, un libro de sonetos y un especial de stand-up comedy solo pueden explicarse de forma plena a partir de conceptos como el de ostensión, inferencia, entorno cognitivo, intención comunicativa, capacidad metarrepresentacional, acto de habla, explicatura, implicatura (fuerte y débil), criterio de relevancia, efectos cognitivos o responsabilidad.

No obstante, el hecho de que la tradición los haya catalogado como discursos muy distintos, y no solo por las diferencias entre rasgos formales o funciones, sino subordinando unos a otros, otorgándoles una predominancia o "normalidad" mayor según criterios difíciles de defender, desvela la intuición de que existen variaciones notables y determinantes entre estos tres lenguajes. La tesis principal que vamos a defender aquí es que cada uno de ellos se centra en uno de los aspectos tratados por la teoría de la relevancia. Desde nuestro punto de vista, el discurso coloquial pone el foco en la realización del acto de habla y en sus beneficios directos; el lenguaje humorístico, en los tres procesos que transforman la forma proposicional de un enunciado en explicatura; el lírico, en las implicaturas débiles, colaterales a toda comunicación.

Con esto queremos decir que para los tres discursos se enriquece la explicatura, se participa en un acto de habla y se generan implicaturas débiles, pero: no siempre existe un juego inesperado con el enriquecimiento, no siempre el acto de habla es lo más relevante y no siempre se generan tantas implicaturas débiles ni, en consecuencia, estas resultan importantes en el acto comunicativo. Hagamos un breve análisis particularizado.

Empecemos por el aparentemente más sencillo, o al menos el más trabajado por los lingüistas: el lenguaje cotidiano. Lo que defendemos es que el lenguaje cotidiano condensa su relevancia en el acto de habla, en la relación entre mensaje e intención. Es más importante afirmar, negar, desear, comprometerse... que hacerlo de cierta manera o que provocar ciertos efectos que dependen tanto del receptor como del emisor, es decir, 
no controlables y provocados sin una responsabilidad real. Prima, por tanto, el beneficio directo de la comunicación: la acción en sí, aplicada y referida al mundo empírico.

Por ello, el discurso coloquial presenta esta tendencia a no requerir grandes inversiones cognitivas en los procesos de construcción de la explicatura; su rentabilidad no recae en cómo es el proceso comunicativo, sino en el acto de habla. Al mismo tiempo, se desatiende la perfección del código, de la forma; esto es, hay cierto descontrol ante la posibilidad de generar implicaturas débiles dirigidas, precisas, buscadamente elocuentes. El receptor, que encuentra la satisfacción de la relevancia con la simple interpretación del mensaje en términos de acto de habla con una implicatura fuerte, no les dedica su atención y su esfuerzo. El paisaje connotativo pasa a segundo plano ${ }^{4}$.

Esta explicación no niega la existencia de un discurso coloquial con elementos poéticos o cómicos, por supuesto. De hecho, es común incluir herramientas de estos lenguajes: el uso de un término muy connotado, un símil, una historia de ficción intercalada ${ }^{5}$, un juego de palabras, un doble sentido... resulta algo habitual en el habla del día a día. Esto verdaderamente supone un argumento a favor de nuestra primera tesis: son discursos que cohabitan en un mismo macroproceso comunicativo. Solo que, en el caso del lenguaje coloquial, el acto de habla es más importante que el resto de los mecanismos y efectos que conforman la comunicación.

\section{UN PROCESO, MUCHOS USOS (II): LA POESÍA COMO ACUMULACIÓN DE IMPLICATURAS DÉBILES}

En el caso del lenguaje poético —y aquí seguimos a García Berrio y Hernández Fernández (2004) en su distinción entre lo poético y lo literario-, la forma guarda un interés mucho mayor. Sperber y Wilson definen como poéticos aquellos efectos "característicos de un enunciado que consigue la mayoría de su relevancia a través de una amplia gama de implicaturas débiles" (1994: 272). Es decir, que ponen la mirada en la creación de muchas implicaturas débiles, simultáneas, cuyo peso en conjunto es capaz de sostener la relevancia de un discurso sin una implicatura fuerte y evidente para el receptor $^{6}$. En este sentido, el discurso poético constituye el otro polo de la comunicación con respecto al discurso cotidiano, en un continuum entre casos de relevancia directa,

\footnotetext{
4 En cierta manera aquí estamos haciendo una crítica a Grice (1957): las máximas comunicativas funcionan de forma más flexible de lo que él proponía, porque en el discurso cotidiano no importa la precisión, sino hacer llegar un mandato grueso, más o menos perfilado, a nuestro interlocutor. El lenguaje coloquial no permite un esfuerzo y una precisión cognitiva tan exacta (demasiado reflexiva y costosa para el gran número de interacciones comunicativas que tenemos a lo largo del día).

5 No estamos pensando en el mensaje que trata sobre una obra de ficción: ese tipo de lenguaje no es poético, simplemente tiene como referentes entidades ficcionales. Aquí hacemos alusión, más bien, a expresiones del tipo a todo cerdo le llega su San Martín, que, en los casos menos tipificados, esto es, en los casos donde el significado no está codificado de antemano, favorecen una interpretación en virtud de sus implicaturas más débiles.

${ }^{6}$ Quizá estamos definiendo algo parecido a lo que Barthes denominó susurro de la lengua (1994c).
} 
clara, poco exigente desde un punto de vista cognitivo, y casos de relevancia escondida, que invitan a la relectura, a la reflexión, a tomar nota de lo mínimo y de lo sugerido.

La variación propia de las interpretaciones de obras líricas es explicada por esta ausencia de mensaje fuertemente manifiesto, de inferencia clara y abiertamente intencional por parte del emisor. Hablábamos antes del símil: cuando un emisor nos compara dos elementos que a priori no se parecen, no nos quedamos en el primer rasgo o atributo que se nos ocurre; nos vemos obligados a rebuscar en las implicaturas, a hallar una recompensa por el trabajo extra. Si nos comparan a alguien con un frigorífico solo para decirnos que es, por ejemplo, una persona ancha, ¿por qué no nos han dicho directamente es una persona ancha? El principio de relevancia nos exige indagar más, obtener más información, buscarle las vueltas. El símil, como la metáfora, gramatiza una relación que requiere inferencias para ser comprensible. También mencionábamos la ficción intercalada: cuando leemos una novela, al igual que cuando se cuenta un refrán que remite a seres, espacios y tiempos ficcionales, el hecho de que el texto no refiera entidades del mundo empírico nos supone un esfuerzo añadido que hemos de rentabilizar. El escritor que quiere decir que en la España rural las mujeres viven atadas a una tradición machista y siniestra no escribe La casa de Bernarda Alba, sino que redacta: "En la España rural las mujeres viven atadas a una tradición machista y siniestra". La exigencia hermenéutica de La casa de Bernarda Alba ha de aportarnos, de la manera que sea, algún beneficio que vaya mucho más allá que la mera transmisión de ese enunciado.

Una vez más, esto no quiere decir que el discurso poético rechace el coloquial o el humorístico. El choque formal que supone un chiste puede ayudar a provocar la erupción de implicaturas débiles definitoria de lo lírico. A su vez, es posible captar lo poético en lo cotidiano, esto es, es posible valorar las connotaciones y las inferencias más sutiles que se desprenden de un texto sin que esto deshaga el acto de habla. Precisamente, los cambios en el canon artístico muchas veces han desvelado que un mensaje que había estado siendo descodificado como no-poético escondía un interés lírico que había que saber encontrar: el género ensayístico es un buen ejemplo de ello.

\section{UN PROCESO, MUCHOS USOS (III): EL HUMOR EN LO INESPERADO}

Si el discurso coloquial pone peso en el acto de habla y el poético en las implicaturas débiles, el discurso cómico enfatiza los procesos pragmáticos que serán los cimientos donde se construyen tanto el acto de habla (en tanto que actitud de la explicatura o implicatura fuerte) como las implicaturas débiles: propone reasignar referentes, redesambiguar palabras, reenriquecer significados, corromper inferencias y provocar cambios bruscos en los entornos cognitivos. Su centro no reside en los efectos finales de la comunicación, sino en el proceso para llegar a ellos: el acto de habla y las implicaturas débiles pasan a un segundo plano, solo resulta necesario el giro imprevisible en el camino hasta alcanzarlas, el recorrido sinuoso, lleno de trampantojos y equívocos, que nos 
conduce hasta la relevancia final. Ni en el lenguaje cotidiano ni en el artístico son estrictamente imprescindibles la sorpresa y la interpretación truncada (lo que para nada quiere decir que sean imposibles o incompatibles; de hecho, pueden considerarse buenos detonantes para la proliferación de implicaturas débiles, tal y como veníamos diciendo).

Veamos cómo se logra esa sorpresa según los distintos elementos del macroproceso comunicativo. Un chiste en su estructura clásica (premisa-remate) tiende a utilizar un término pivote (Hockett, 1972), esto es, un término que cuenta con más de una acepción, susceptible de ser reenfocado. Los oneliners de Luis Álvaro ejemplifican bien este proceso: "Cuando alguien habla de hacer brainstorming pienso en Lee Harvey Oswald" o "Juan Carlos I y los españoles después" son dos tuits recientes de este cómico en los que los pivotes brainstorming y $I$ cambian de significado a medida que avanza la recepción del mensaje. De una reunión a un asesinato y de un nombre propio a una posición social. El hecho de que en el segundo caso podamos obtener inferencias, bosquejar una lectura política (pero a partir de implicaturas débiles: es imposible asegurar a ciencia cierta que Luis Álvaro sea antimonárquico aunque esa conclusión sea deducible de su chiste), no es determinante para que la comedia funcione ${ }^{7}$.

Otra posibilidad de retorcer los mecanismos del proceso comunicativo es la de conseguir implicaturas (ya no explicaturas) inesperadas. Una estrategia recurrente consiste en resquebrajar las premisas que están a medio componer, proponer giros radicales en la conversación. Acudamos a los tuits de otro cómico, Iggy Rubín, para entender mejor este fenómeno: "Se ha olvidado muy rápido que Otegi militó en ETA y Beyoncé en Destiny's Child” pretende hacer saltar nuestro entorno cognitivo, remueve dos campos que (en la mayoría de las personas) no acostumbran a estar activos y manifiestos a un mismo tiempo, como son ETA y Destiny's Child. En ese contraste abrupto irrumpe la comedia, desubicando al receptor por unos segundos.

Algo parecido, en un nivel meta, sucede con las actuaciones de Ignatius, un cómico transgresor en lo formal y que, precisamente, juega con las estructuras típicas del standup que acabamos de exponer. Tan pronto propone - muy enfáticamente - una premisa que luego se descubre sin remate como se detiene a reflexionar sobre lo ridículo que resulta en su labor de cómico, se embarra, se traba, se repite. Las premisas implicadas, el marco, guion o esquema cognitivo (Fillmore, 1982), el horizonte de expectativas que uno

\footnotetext{
${ }^{7}$ Aprovechamos para recordar que siempre hay implicaturas débiles. No sería extraño que alguien nos criticase el no señalar implicaturas en el primer tuit: efectivamente, podría entenderse que, para Luis Álvaro, el brainstorming — concepto entre lo hípster y lo neoliberal— es equiparable a un tiro en la cabeza. Al fin y al cabo, él es cómico y guionista, conoce el trabajo en grupo y sus dificultades. En este caso, incluso, la metáfora es más arriesgada que con el chiste sobre Juan Carlos I: el trabajo del receptor es mayor, los efectos poéticos podrían verse magnificados. También, por otra parte, la responsabilidad del autor quedaría más diluida. Con todo, nuestro propósito no era sino señalar cómo el centro de la broma, se capten esas implicaturas débiles o no, reside en el giro del proceso pragmático: en la interpretación que se queda a medio camino y obliga a un replanteamiento total del sentido del mensaje en medio de su recepción.
} 
asocia al género, los tipos de acto de habla que habitualmente ligamos al monólogo cómico... se van al garete. Y, en su destrucción sorpresiva, surge el humor ${ }^{8}$.

\section{TRES LENGUAJES (QUE PUEDEN LEERSE) ENTRELAZADOS}

Creemos haber propuesto una teoría sólida que explica el modo en que los discursos cotidiano, poético y cómico se configuran en torno a distintos elementos y procedimientos de un mismo macroproceso comunicativo. No obstante, nos gustaría incluir algunos textos híbridos en los que poder comprobar cómo estos lenguajes conviven en un único mensaje: tres comentarios cualesquiera, tres oneliners, tres versos. Una de las ventajas de la propuesta que aquí defendemos es que no forzamos la separación de los lenguajes, sino que los catalogamos según tendencias ${ }^{9}$ dentro de un espíritu común: la comunicación. Hallar textos al mismo tiempo coloquiales, líricos y humorísticos nos parece un argumento de peso para nuestra tesis principal.

Frente a casos como un "hola" al entrar en la oficina por la mañana, Mrs. Dalloway o un chiste de El Club de la Comedia, casos que cabría consensuar como monodiscursivos, existen multitud de mensajes en que los tres lenguajes se entrecruzan. Comenzaré con una anécdota personal que, desde mi punto de vista, ejemplifica este fenómeno. La historia que quiero relatar sucedió en una cafetería. Yo estaba en una mesa, cuando vi entrar a una mujer notoriamente bizca, que se acercó a la barra y le dijo a la camarera: "Carmen, qué bien te veo". En estas cuatro palabras están concentrados todos los procesos vistos hasta el momento. Por un lado, aparece el acto de habla coloquial saludar, asociado a una explicatura que podría parafrasearse en 'estás bien y me alegro por ello'. Por otro, se propone una resignificación cómica de la locución ver bien: primero significa 'encontrar con salud' y después 'observar sin problemas de vista'. Por último, el enunciado despierta algunas inferencias muy débiles de cierto valor poético, como la posibilidad de la ironía (una pronunciación "fingida" o ecoica, esto es, en cierta manera ficcional) que claramente no estaba siendo propuesta pero que sí aparecía sugerida, con su correspondiente construcción de personaje a partir de su vestimenta, su joyería, su manera de andar, su maquillaje, su quinesia, prosodia y gestualidad..., todo ello con un ligero aire almodovariano, entre lo kitsch y lo cínico.

El segundo ejemplo lo tenemos en la cita que abre este artículo. "What this show is is a metaphorical preposition that explains the relationship of between what you think you think you see me think and what I'm genuinely able to think", afirma Gadsby en su

\footnotetext{
${ }^{8}$ Por cierto, uno de los mensajes poéticos, inferido débilmente, de la propuesta performativa de Ignatius no es sino una confirmación de la teoría de la relevancia: la opción de que dos personas muy distintas entre sí puedan empatizar y colaborar en la situación más bochornosa, absurda y triste, precisamente porque es bochornosa, absurda y triste para todos. Ignatius nos descubre un universal. Toda persona está buscando comprender, interpretar; por eso, uno de los elementos que más nos une es la posibilidad latente del fracaso comunicativo. Pero ese es otro artículo.

${ }^{9}$ Esperamos que aquí resuene una concepción cognitivista del lenguaje y la construcción de categorías mentales, con poso en Wittgenstein, de la teoría de prototipos o la teoría de schemata.
} 
segundo y polémico especial de stand-up para Netflix. Aunque parece que busca, humorísticamente, ridiculizar un prejuicio generalizado sobre lo que es hacer comedia, romper la premisa (y desmontar todo proceso inferencial que la tuviera como premisa implicada), simultáneamente afirma — da una opinión ante la que se posiciona como creyente - sobre las intenciones de su stand-up comedy. Y, además, provoca una serie de implicaturas débiles que, pensamos, son de especial interés y generan cierta poeticidad: subrayan el carácter imposible de una comunicación literal (a metaphorical preposition), evocan la incomprensibilidad de uno mismo (what you think you think) y señalan el complejísimo proceso que es la transmisión de información, tan complejo que resulta complejo el mero hecho de describirlo, tan complejo que parece absurdo.

Por último, he seleccionado una cita de Mother Night, una novela de Kurt Vonnegut: "Be careful what you pretend to be because you are what you pretend to be" (2000: vii). El contexto, a diferencia de lo que ocurre en los ejemplos anteriores, nos lleva a indagar en el carácter artístico de este texto en primer lugar. No hace falta aclarar que los efectos poéticos de la novela solo pueden ser rescatados si atendemos a la obra en su totalidad, si hacemos contrastar la sentencia del narrador con las vivencias y las psicologías de los personajes, con el desarrollo de los acontecimientos y el estilo en que estos son narrados; pero, por cuestiones prácticas, vamos a remitirnos solo a esa línea. Vonnegut parece sugerir nuevas conexiones entre la apariencia y la realidad, nos descubre cómo nos relacionamos con nosotros mismos y con el resto de la sociedad, con las acciones que llevamos a cabo y la imagen que estas reflejan hacia el exterior. Y lo hace mediante las implicaturas débiles, a veces muy débiles. Esto no quita para que tales efectos sean obtenidos gracias a un giro retórico, cómico, sustentado en el significado de la palabra pretend, término pivote que pasa de significar 'lo que no es' a 'lo que es, porque es lo percibido' o 'lo que es, porque es lo que se hace' (el matiz no está claro o, mejor dicho, es abiertamente plural: de ahí que produzca múltiples efectos poéticos). Asimismo, es posible asociar esta oración al discurso coloquial: en el fondo es un enunciado que podía haberse pronunciado en un contexto cualquiera, que podía habernos lanzado Vonnegut mientras tomamos un café: se transmite información, se afirma una idea, se defiende su veracidad, se logra un cambio del entorno cognitivo del receptor, que después de interpretar la frase debería parecerse un poco más al entorno cognitivo del emisor. No podemos negarnos a ver en la frase de la novela de Vonnegut una frase de Vonnegut, con todo lo que eso implica.

\section{HIBRIDAR Y SUS CONSECUENCIAS}

Antes de terminar, nos parece necesario detenernos en algunos puntos ciegos de la teoría que acabamos de proponer. La opción de definir ciertas realidades culturales que normalmente están contrapuestas en términos de tendencias, esto es, abriendo la posibilidad de que puedan compartir un mismo espacio, no puede agotarse en una descripción de lo prototípico. Las fronteras porosas que las separan (y, en cierta medida, 
las unen) han de ser también estudiadas; es allí, en su fuzzy limit, donde se pueden comprobar cómo se relacionan, qué efectos provocan, qué posibles subgéneros brotan.

El caso más sencillo de comentar es el de la frontera entre los discursos poético y cómico. Los estudiosos de la comedia no han tardado en señalar cómo el humor suele estar asociado con los efectos cognitivos propios de lo lírico (Núñez Ramos y Lorenzo, 1997). Nosotros ya hemos defendido que el hecho de que compartan el macroproceso comunicativo, junto con el discurso coloquial, no significa que todo mensaje cómico deba ser leído en términos de poesía. Es cierto, sin embargo, que el tipo de proceso que define la comicidad tiende a producir una actitud que favorece la recepción poética, esto es, la recepción atenta a las implicaturas más débiles y más alejadas del texto. Pero ni es necesario para considerar relevante el chiste o el monólogo, ni sucede siempre.

De manera simétrica, cuando pensamos en la poesía como sorpresa y revelación, a la manera de Vicente Huidobro, estamos cayendo en la misma difuminación. Según nuestra propuesta, el elemento lírico puede aparecer desde la frialdad total, sin sorpresa, desde el convencionalismo, leyendo lo que ya habíamos leído, pero cambiando el objetivo de la lectura: centrándonos en las implicaturas débiles que el texto despierta en nosotros. Que las propuestas vanguardistas o neovanguardistas motiven la asunción de un tipo de actitud afín a lo cómico - leer y escuchar desde la sorpresa - no deja de ser secundario ${ }^{10}$.

En lo que respecta a los lenguajes cotidiano y cómico, consideramos que los resultados de su hibridación se pueden percibir muy bien analizando los distintos tipos de monólogo cómico. Desde el oneliner al performativo, pasando por el relato de anécdotas y los bloques monotemáticos, es posible determinar varios niveles de asunción de la intención del autor: la figura de la persona que actúa con sus palabras, que efectivamente afirma (y nos dice que afirma), cree (y nos dice que cree), cambia según el estilo del cómico, entre otros rasgos determinantes. En algunos de ellos, la autoficción que se genera asume un papel entre lo gracioso y lo coloquial, entre la búsqueda de la risa y la sensación de certeza propia de la no ficción.

En sentido opuesto, los elementos humorísticos — también los poéticos- en el lenguaje cotidiano colorean las conversaciones. Son elementos retóricos, de apoyo, subyugados al acto de habla, pero que vuelven más atractiva (y, por tanto, menos costosa cognitivamente) la transmisión de información, la petición, la promesa o el simple hacer pasar tiempo en un ascensor que el emisor esté intentando llevar a cabo. Una conversación cotidiana bien maquillada con bromas o figuras retóricas siempre resulta más agradable que una seca, tipificada o torpe.

Por último, queda analizar la frontera entre lo poético y lo coloquial desde el punto de vista del primero. Ya se señaló hace unas páginas que la hibridación de ambos

\footnotetext{
${ }^{10}$ Hay que señalar que los textos literarios producen efectos poéticos, aunque su estructura formal y de contenido no sea tan agresiva como la de los vanguardistas precisamente porque son literarios: porque están institucionalizados como tal y, por tanto, nos acercamos a ellos con un guion de lectura en el que se recomienda atender a las implicaturas débiles. No nos hace falta la sorpresa: venimos ya sorprendidos, aprendimos la sorpresa de la sociedad en que hemos crecido, estudiado y a través de la cual hemos experimentado la realidad.
} 
discursos ha tenido consecuencias notorias en el canon literario. Una tesis como la que aquí se defiende coloca a los estudios literarios en el brete de no poder delimitar su campo de estudio: ha de revisarse constantemente qué es y qué no es poesía, en un gesto (de nuevo) barthesiano. No obstante, todo esto esconde algunos problemas interesantes que hemos de tratar con mayor profundidad.

\section{ALGUNAS IMPLICACIONES (I): LA FICCIÓN, EL AUTOR Y EL YO DE LA ENUNCIACIÓN}

Queremos terminar con una coda, una invitación a la investigación que parte de las tesis aquí defendidas. Es habitual tratar de fomentar la labor académica del campo propio, pero en esta ocasión vamos a incidir en un aspecto aparentemente endeble de nuestra teoría.

Si aceptamos lo dicho hasta ahora en el plano pragmático, surge el problema de cómo considerar los textos en el plano lógico-semántico. Hemos diferenciado atributos de lectura, de interpretación, pero apenas nos hemos detenido en la forma del discurso ni en qué y cómo referencian. Esta cuestión es especialmente importante en un contexto como el presente, ya que una de las distinciones clásicas entre discurso coloquial y poético reside en el concepto de ficción. No es nuestra intención desmontar las teorías lógicosemánticas de la ficción, algo que conllevaría muchas páginas de análisis pormenorizado de las diversas posturas que se han pronunciado sobre ello. Pero sí queremos incidir en cómo las teorías de la doble imitación platónica —incluso la de cierta mímesis aristotélica-, las propuestas de algunas teorías del realismo o, grosso modo, toda la corriente de la lógica filosófica y de teoría de mundos posibles que ha tratado de discernir entre textos ficcionales y textos no ficcionales no se adecúan a las ideas defendidas en este artículo. Es decir: que, desde nuestro punto de vista, yerran en sus premisas. A diferencia de lo que estos filósofos y teóricos opinan, creemos en la posibilidad de que un texto pueda ser simultáneamente coloquial, acto de habla efectivo, y poético, amasijo de implicaturas débiles: un texto puede ser al mismo tiempo ficción y no ficción.

Al fin y al cabo, ya hemos insistido en ello en varios momentos, cuanto más nos acercamos a la explicatura y las implicaturas fuertes, más responsabilidad cargamos sobre los hombros del emisor: más pegado está el mensaje al yo de la enunciación. Cuanto más nos acercamos a las implicaturas débiles, por el contrario, más responsabilidad cargamos sobre nuestros hombros de receptores: el yo de la enunciación se aleja, pasa a un segundo plano, deja de ser tan importante en favor de las inferencias posibles, múltiples, minúsculas, que nacen en el vacío entre el final del texto y el comienzo de nuestra interpretación. Creo que esta idea tiene sentido con lo que, intuitivamente, entendemos como ficción: un texto desapegado, alejado de la enunciación, un texto que puede ser recontextualizado, que termina por no remitir directamente a lo empírico, que habla lateralmente, desde un lugar impreciso, que nos pide, como lectores, un ejercicio de imaginación y de compromiso. Así es la definición habitual de lo que solemos llamar 
clásicos: son libros que renuevan su significado con cada lectura y, en ese sentido, libros dichos por nadie.

Que el texto construye la (no) ficcionalidad como un continuum también se puede comprobar en el lenguaje cómico. Hemos afirmado que este tipo de discurso se centra en los recursos y mecanismos con los que construimos la interpretación; esto es, que a veces tiene en cuenta al sujeto enunciador y a veces no, dependiendo de si el chiste en concreto requiere activar supuestos sobre lo que sabemos de él o si el chiste se puede entender resulta relevante - como mero juego lingüístico, del código, sin tener en cuenta a quien lo dice. En otras palabras, el texto humorístico fluctúa, transita, desde el polo no ficcional al polo ficcional según le venga bien, solo si el criterio de relevancia se lo exige. También por eso muchas veces no tiene siquiera sentido tratar de distinguir si un monólogo es ficción o no: simple y llanamente, no es un criterio relevante.

A la luz de fenómenos como el del stand-up comedy se han acuñado términos teóricos difíciles de definir. Un ejemplo popular en los últimos años es el de la autoficción. Consideramos que la teoría de la comunicación que hemos defendido permite explicar de qué manera funciona este concepto. El texto que cae en la categoría de lo autoficcional es aquel que mantiene en alerta al receptor, que lo coloca en el filo $-\mathrm{o}$, mejor, en el continuum - de la (no) ficción. En ocasiones, el beneficio que extraemos por interpretar un enunciado en términos de no ficción es muy alto; en otras ocasiones, no lo suficiente. A veces obtenemos mucho rédito de una lectura ficcional; otras, no tanto. La cuestión es que somos capaces de entender el mensaje como un acto de habla del autor real, agenciarle responsabilidad sobre lo que dice, y a la vez captar un buen número de implicaturas débiles, quitarle el texto de las manos y mirarlo en el vacío, a contraluz, contra nosotros mismos.

¿Cuál es, por tanto, la definición de ficción que se desprende de la interpretación pragmática, según la teoría de Sperber y Wilson, de los distintos discursos? La ficción es un tipo de recepción que puede ser simultánea o no a una recepción coloquial o cómica tal y como las hemos descrito, caracterizada por la obtención de relevancia comunicativa a través de la apropiación del texto por parte del lector o escuchante, arrancando el peso del yo de la enunciación y desligándolo del contexto de emisión (aunque siempre queden restos). Da igual si el mundo referenciado es el factual, es realista, es fantástico; en ese gesto de desgarro el referente exacto se pierde, a la par que se ganan los efectos poéticos ${ }^{11}$.

Decíamos en el anterior paréntesis que siempre encontramos huellas de la enunciación. Esto es así: al igual que en toda comunicación hay acto de habla, desambiguación, explicatura, implicatura, etcétera, también en la literatura de ficción quedan restos del yo original. Nunca dejamos de lado la idea de que hay un yo. De ahí las corrientes biografistas, historiográficas, positivistas, todavía predominantes en los

\footnotetext{
11 Remitimos al clásico texto de Barthes (1994a), "La muerte del autor", donde se habla de ese alejamiento del Autor en pos de un predominio del texto como pluralidad. Evidentemente, su postura nos parece ligeramente exagerada, pero muy certera y comprensible por el momento histórico en el que se enmarca. Los distintos tipos de discurso provocan, de forma coherente, distintos efectos. Nosotros proponemos que, en algunas ocasiones, es posible hacer convivir Autor y texto plural.
} 
estudios literarios de nuestro país; de ahí el "basado en hechos reales" de las películas (como si hubiera alguna basada en otro tipo de hechos); de ahí la solapa con la vida del autor, las fotografías y las ruedas de prensa para publicitar el libro. El autor de ficción no estuvo nunca muerto, simplemente no era apenas importante, relevante, necesario para una comunicación satisfactoria. Mejor lo colocamos en la sombra, pero a mano, por si en algún momento nos hace falta.

\section{IMPLICACIONES (II): MUNDOS, PALABRAS Y FICCIONES DE PRIMER ORDEN}

En un sentido inverso, también hay que explicar cómo hacer confluir ficción y no ficción en el otro polo de la comunicación. No solo estamos defendiendo que la ficción puede ser leída como un acto de habla cotidiano, sino también que el discurso coloquial puede ser leído como ficción. ¿Cómo casa esta idea con la teoría pragmática?

Ya que la teoría de la relevancia admite desde el primer momento la existencia de algunos vacíos o saltos necesarios para la interacción del ser humano con el mundo (que tenemos que salvar con un ejercicio activo: suponemos el entorno cognitivo del interlocutor, deducimos la asignación de referentes, la desambiguación y el enriquecimiento, construimos — nosotros, receptores - la explicatura, interpretamos y no solo desciframos los posibles sentidos del enunciado y el acto de habla que se ha llevado a cabo), esta permite explicar la manera en que mediamos entre entes física y objetivamente diferentes pero que tenemos que poner en relación (objetos y palabras, palabras y sentidos, sentidos e intenciones), en una nube de mundos posibles ya adelantada por Goodman (1990). La teoría de la relevancia se ajusta a la propuesta de Fauconnier y Turner de la fusión conceptual (2002), por la que nos servimos constantemente de la analogía para entender lo que nos rodea; cuando participamos en una conversación cualquiera, pero también cuando disfrutamos de un poema o nos sonreímos con un chiste, estamos llevando a cabo un acto intrínsecamente creativo, de origen genético común (Lorenzo, 2021) y mediante los mismos procesos con independencia del tipo de discurso.

Así, puede decirse que empleamos el código lingüístico para construir ficciones, que el receptor lee en términos de actos ligados a la intención autorial, de efecto cómico o efecto lírico según ciertas particularidades que luego comentaremos. Porque nuestra relación con lo externo a nosotros (incluso con lo interno) es de acercamiento metafórico, de conceptual blending, de asunción de analogía, concurrencia y solapamiento. A riesgo de sonar demasiado cercanos a Hume (2001), diremos que es una relación labrada por la costumbre sobre la que imprimimos causas, efectos o intenciones que no están sino en nosotros mismos y en nuestra experiencia.

A todo esto, hay que hacer una aclaración importante. Lo que nos evita caer en la llamada doctrina panficcional (Ryan, 1997), en considerar que absolutamente todo es ficción, es la idea de que no todo mensaje es relevante por ser ficcional. Cuando la 
relevancia se consigue mediante el distanciamiento del yo de la enunciación, bienvenido sea ese distanciamiento. Cuando, en cambio, necesitemos un yo fuerte, asociado a un acto de habla, la baja rentabilidad que supondría distanciarlo hará que ese alejamiento no se lleve a cabo. De hecho, las cosas no son ficción, sino que son leídas como ficción. La ficción es, reiteramos, una actitud de lectura.

En consecuencia, la idea difundida de que la literatura es un lenguaje de segundo orden, de que la ficción está subyugada al habla cotidiana, no se sustenta. Tampoco la hipótesis de que la ficción funciona como un acto de habla fingido (Searle, 1975). Hemos de reformular ambos postulados: es cierto que la literatura tiende a reflexionar de manera activa sobre el propio código, más que el discurso coloquial, pero nace del mismo lugar que la charla o la broma y no finge nada. El acto fingido, aseguraba Martínez Bonati (1997), no es efectivo. Y es indudable que la literatura es efectiva. Más bien — creemosel mensaje poético se esconde en un acto de habla para hablar de otra cosa, más allá del acto en sí, en torno al acto en sí y, a veces, en contra del acto en sí. De este modo se afianza la concepción de la ficción no como un objeto estudiable desde el paradigma lógico-semántico, en la línea platónica o de la teoría de los mundos posibles, sino como un factor pragmático, de tipo de lectura, que puede convivir con distintas realidades lógico-semánticas (Nielsen, Phelan, Walsh, 2015a; 2015b).

\section{IMPLICACIONES (III): LA ACTITUD, EL CANON Y LOS ESTUDIOS LITERARIOS}

Una tercera implicación de la tesis de este artículo es la necesidad de volver a pensar el concepto de actitud. Al problematizar la dicotomía entre ficción y no ficción, entre lenguaje cotidiano y lenguaje poético, hemos puesto el foco en los efectos del mensaje lingüístico: todo mensaje es acto de habla y todo mensaje provoca implicaturas débiles, pero atender a uno o a otras es lo que diferencia la recepción. De lo que se deduce que la lectura poética es una cuestión de perspectiva; si, ante cualquier texto, nos fijamos en los brillos connotados, en lo sugerido, en lo que está más allá, ese texto se vuelve lírico. O lo que es lo mismo: la actitud de lectura resulta uno de los elementos definitorios de la poeticidad. Somos conscientes de que la forma y el contenido del texto condicionan esa actitud: uno puede luchar solo hasta cierto punto contra los signos. Pero siempre nos quedará la opción de desenmarcar el enunciado de su contexto original y no hacer caso del yo de la enunciación, a ver qué sucede. Otra cosa será que los efectos poéticos no resulten rentables y hayamos hecho el esfuerzo cognitivo en vano.

Esta teoría es acorde con el modo en que experimentamos la literatura. En las obras en que se cumplen las convenciones que, en nuestra sociedad y en nuestro tiempo, dictan lo literario, esta predisposición a atender a lo escondido, a lo tenue y sutil, a lo que requiere una vuelta de tuerca y una inferencia más de la esperada, el proceso comunicativo de tipo lírico sucede de forma mecánica. Nos dan algo como literatura y tendemos a leerlo como tal. Lo mismo sucedía con las formas vanguardistas, tal y como comentamos hace 
unas páginas, donde el mero choque de expectativas $-\mathrm{y}$ tal vez ese choque está ya convencionalizado en nuestra sociedad y ha dejado de ser ningún choque - nos avisa de que es momento de dirigir la vista hacia las implicaturas.

Sin embargo, hay casos donde esa actitud es autoimpuesta, donde forzamos la relación que mantenemos con el texto, dando lugar tanto a reformulaciones del canon artístico como a innovadores juegos del lenguaje, con vistas a obtener ciertos efectos poéticos. Aprendemos a disfrutar obras ya conocidas cuyo valor artístico nos había pasado desapercibido, como está sucediendo (y como siempre sucedió) con las nuevas formas y los nuevos medios, desde el cine en sus orígenes hasta, ahora mismo, los vídeos de TikTok o las cuentas de Instagram, pasando por las teleseries o los videojuegos; y de vez en cuando hay quien se obliga a leer a contrapelo, como sucede en el texto líricocientífico-académico de García Rodríguez (2016). La poeticidad en muchas ocasiones se encuentra: el prospecto de un medicamento tiene potencial para evocar innumerables inferencias débiles, despierta ideas sueltas, hace brillar cada una de sus palabras con una fuerza inesperada. Y el disfrute de este lirismo, ya sea ante mensajes creados para ello o en mensajes sobrevenidos, es siempre igual de válido y enriquecedor.

Lo que se está planteando aquí es la necesidad de repensar el canon de lo literario desde unas premisas que (casi) vienen a decir que, más que de canon literario, deberíamos hablar de actitud poética, de experiencia poética. Arriba mencionábamos el género ensayístico como un subtipo de textos que solo recientemente se ha entendido como cargado de potencial poético. A este podemos sumarle también el monólogo cómico y otras formas de autoficción. Una propuesta como la nuestra quiere desmontar la manera en que se han estructurado los estudios literarios: parece necesario reorganizar el modelo, revisar el vocabulario técnico, reenfocar las disciplinas. No debemos pensar la literatura exclusivamente en términos de etapas, de autores, ni siquiera de obras, porque estas son clasificaciones volubles y poco atadas a lo que más debería importarnos: los efectos poéticos. Es evidente que la presencia social de esas taxonomías es importante, inevitable hasta cierto punto e incluso beneficiosa: condiciona nuestro horizonte de expectativas, es el marco de referencia para que los textos nos sorprendan, nos parezcan originales, nos den pistas y dialoguen entre ellos. Gracias a que conocemos estas perspectivas disfrutamos mucho más de la literatura. Y es que no hay comunicación sin prejuicio. Pero, al mismo tiempo, parece que estamos cediendo un espacio pensado para la poesía a la repetición de esquemas convencionales, que no exploran el texto como pluralidad y que no atacan al verdadero núcleo de lo literario.

\section{BREVE SÍNTESIS FINAL}

Pero todas estas implicaciones son temas apenas indagados, que quedan para otros trabajos. Hemos mostrado cómo la aplicación de la teoría de la relevancia propone una nueva mirada a la distinción clásica, deconstruida durante el postestructuralismo, entre los discursos coloquiales, poéticos y cómicos, bajo la tesis principal de que es posible 
distinguir diversas tendencias individuales a la vez que se encuentran confluencias comunes: no son lenguajes que se pisan y rechazan, incompatibles, sino varias facetas $u$ objetivos que nos ofrece el macroproceso de la comunicación humana.

Además, hemos buscados las consecuencias de la propuesta pragmática a la hora de repensar conceptos teóricos como ficción, no ficción, yo de la enunciación, actitud, recepción poética, canon, didáctica de la literatura... Esperamos animar nuevos estudios que profundicen en ellos desde una perspectiva más fresca, entendiendo en su conjunto las relaciones comunicativas, y siempre con un ojo puesto en su efectividad retórica: en la relevancia del mensaje.

\section{REFERENCIAS BIBLIOGRÁFICAS}

Althusser, L. (1970). Sobre el trabajo teórico: dificultades y recursos. Barcelona: Anagrama.

Austin, J. L. (1981). Cómo hacer cosas con palabras. Palabras y acciones. Barcelona: Paidós.

BARTHES, R. (1994a). "La muerte del autor". En El susurro del lenguaje. Más allá de la palabra y de la escritura, 65-71. Barcelona: Paidós.

(1994b). "De la obra al texto". En El susurro del lenguaje. Más allá de la palabra y de la escritura, 73-82. Barcelona: Paidós.

(1994c). "El susurro de la lengua". En El susurro del lenguaje. Más allá de la palabra y de la escritura, 99-102. Barcelona, Paidós.

(2005). Crítica y verdad. Madrid: Siglo XXI.

DoležEL, L. (1999). Heterocósmica. Ficción y mundos posibles. Madrid: Arco / Libros. Fauconnier, G. \& TURner, M. (2002). The Way We Think. New York: Basic Books.

Fillmore, Ch. (1982). "Frame semantics". En Linguistics in the Morning Calm, Linguistic Society of Korea (ed.), 111-137. Seoul: Hanshin Publishing.

GADSBY, H. (2020). Douglas, prod. Netflix.

GARCíA BERrio, A. y HERnÁNDEZ FernÁNDEZ, T. (2004). Crítica literaria. Iniciación al estudio de la literatura. Madrid: Cátedra.

GArcía Rodríguez, J. (2016). "Lyrica® (patología y tratamiento)”. Actio Nova. Revista de Teoría de la Literatura y Literatura Comparada 0, 110-121.

GRICE, P. (1957). “Meaning”. The Philosophical Review LXVI.3, 377-388.

HocketT, CH. F. (1972). “Jokes”. En Studies in Linguistics in Honor of George L. Trager, M. Estellie Smith (ed.), 153-178. The Hague: Mouton.

Hume, D. (2001). "De la idea de conexión necesaria". En Tratado sobre la naturaleza humana. Ensayo para introducir el método del razonamiento experimental en los asuntos morales, 126-138. Albacete: Dipualba. 
LORENZO, G. (2021). "La literatura, creoda generativa del lenguaje (o algo lo bastante parecido)”. En Intersecciones, J. García Rodríguez (ed.), 121-155. Oviedo: Servicio de Publicaciones de la Universidad de Oviedo.

Martínez BonAti, F. (1997). "El acto de escribir ficciones". En Teorías de la ficción literaria, A. Garrido Domínguez (comp.), 159-170. Madrid: Arco / Libros.

Goodman, N. (1990). "Palabras, trabajos, mundos". En Maneras de hacer mundos, 1743. Madrid: Visor Libros.

Nielsen, H. S., J. Phelan \& R. Walsh (2015a). "Ten Theses about Fictionality". Narrative XXIII.1, 61-73.

(2015b). "Fictionality as Rhetoric: A Response to Paul Dawson". Narrative XXIII.1, 101-111.

NúÑEz Ramos, R. \& Lorenzo, G. (1997). “On the Aesthetic Dimension of Humor”. Humor X.1, 105-116.

RYAN, M.-L. (1997). "Postmodernism and the Doctrine of Panfictionality". Narrative V.2, $165-187$.

SEARLE, J. R. (1975). “The Logical Status of Fictional Discourse”. New Literary History VI.2, 319-332.

SPERBER, D. Y WiLson, D. (1994). La relevancia. Comunicación y procesos cognitivos. Madrid: Visor Libros.

VonNEGUT, K. (2000). Mother Night. London: Vintage.

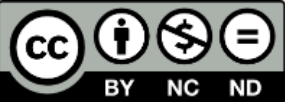

This work is licensed under a Creative Commons AttributionNonCommercial-NoDerivatives 4.0 International (CC BY-NC-ND).

Fecha de recepción: 14/01/2021

Fecha de aceptación: 31/05/2021 